\title{
Utility of convex EUS for preoperative vascular evaluation of malignant biliary tract neoplasm
}

\author{
AKASHI FUJITA ${ }^{1}$, KAZUO HARA ${ }^{1}$, NOBUMASA MIZUNO ${ }^{1}$, SUSUMU HIJIOKA ${ }^{1}$, TAKAMICHI KUWAHARA ${ }^{1}$, \\ NOZOMI OKUNO $^{1}$, YASUHIRO SHIMIZU ${ }^{2}$, YOSHIKI SENDA ${ }^{2}$, SEIJI NATSUME ${ }^{2}$ and YASUMASA NIWA ${ }^{3}$
}

\author{
Departments of ${ }^{1}$ Gastroenterology, ${ }^{2}$ Gastroenterological Surgery, and ${ }^{3}$ Endoscopy, \\ Aichi Cancer Center Hospital, Nagoya 464-8681, Japan
}

Received September 23, 2017; Accepted November 22, 2017

DOI: $10.3892 /$ mco.2017.1544

\begin{abstract}
The aim of the present study was to examine the utility of convex endoscopic ultrasonography (EUS) for the preoperative vascular evaluation of malignant biliary tract neoplasm, by comparing EUS findings with histological findings from resected specimens. Between January 2008 and January 2016, the present study retrospectively retrieved 82 cases diagnosed with malignant biliary tract neoplasm to compare findings from convex EUS with histological findings from resected specimens. A total of four groups were defined according to the results of EUS of the hepatic artery (HA) and portal vein (PV): Group 1, hyperechoic tissue between tumor and vessel; group 2, close proximity between tumor and vessel without loss of hyperechoic tissue; group 3, tumor and vessel contiguity, with loss of hyperechoic tissue; and group 4 , encasement $>180^{\circ}$. Regarding the HA, all 17 cases in groups 2 and 3 in which the tumor was close to the HA however no obvious encasement was evident, demonstrated no histological invasion, or the HA could be separated from the tumor intraoperatively. However, this was not the case for the portal vein. Of the six cases in group 3, 4 cases (66.7\%) demonstrated PV invasion. Overall, convex EUS is useful for the preoperative evaluation of malignant biliary tract neoplasms, and surgery may be considered when the tumor is close to the HA on computed tomography scans, however there is no obvious encasement visualized by convex EUS.
\end{abstract}

\section{Introduction}

Patients with malignant biliary tract neoplasm, especially cholangiocarcinoma, are increasing and diagnosis is mostly made in the advanced stage (1). For patients with locally advanced or metastatic stage, median overall survival is 11.7 months (2). Although surgical resection offers a chance

Correspondence to: Dr Kazuo Hara, Department of Gastroenterology, Aichi Cancer Center Hospital, 1-1 Kanokoden, Chikusa-ku, Nagoya 464-8681, Japan

E-mail: khara@aichi-cc.jp

Key words: bile duct neoplasm, diagnostic imaging, endoscopic ultrasonography, hepatic artery, portal vein for cure (3), complete resection is sometimes difficult because of vascular invasion resulting in poor prognosis. Since treatment planning and surgical procedures are often determined by the presence or absence of vascular invasion, precise diagnosis is required. Evaluating vascular invasion is thus crucial to curative resection in patients with malignant biliary tract neoplasm. Computed tomography (CT) has been the standard for preoperative evaluation of cholangiocarcinoma until now because of its ability to noninvasively perform. However, vascular invasion has been difficult to assess precisely before surgery. Our hospital has used convex endoscopic ultrasonography (EUS) for preoperative evaluations of malignant biliary tract neoplasm. This modality appears very useful for the assessment of vascular invasion. We can visualize and evaluate the hepatic artery (HA) and portal vein (PV) at high resolution with the careful technique we have reported previously (4). However, we do not have clear criteria for vascular findings from EUS or how to take advantage of vascular evaluation clinically. The usefulness of vascular evaluation using EUS in pancreatic cancer cases has been reported $(5,6)$, but no reports have described in detail the use of this modality for malignant biliary tract neoplasm. The aim of this study was to examine the utility of convex EUS for the preoperative evaluation of malignant biliary tract neoplasm by comparing EUS findings with histological findings from resected specimens.

\section{Patients and methods}

Between January 2008 and January 2016, a total of 150 patients who had been diagnosed with malignant biliary tract neoplasm (intrahepatic/extrahepatic cholangiocarcinoma, gallbladder carcinoma, or cystic duct carcinoma) underwent surgery at Aichi Cancer Center Hospital. We performed EUS as preoperative evaluation in 82 cases of them and retrospectively retrieved for the comparison of convex EUS findings with histological findings from resected specimens. We excluded patients who did not undergo EUS before surgery. All patients provided written informed consent for EUS, and this study was approved by the Institutional Review Board of Aichi Cancer Center Hospital (approval no. 2016-1-322).

Preoperative evaluation. We performed EUS at $7.5-\mathrm{MHz}$ frequency using a convex linear-array echoendoscope 


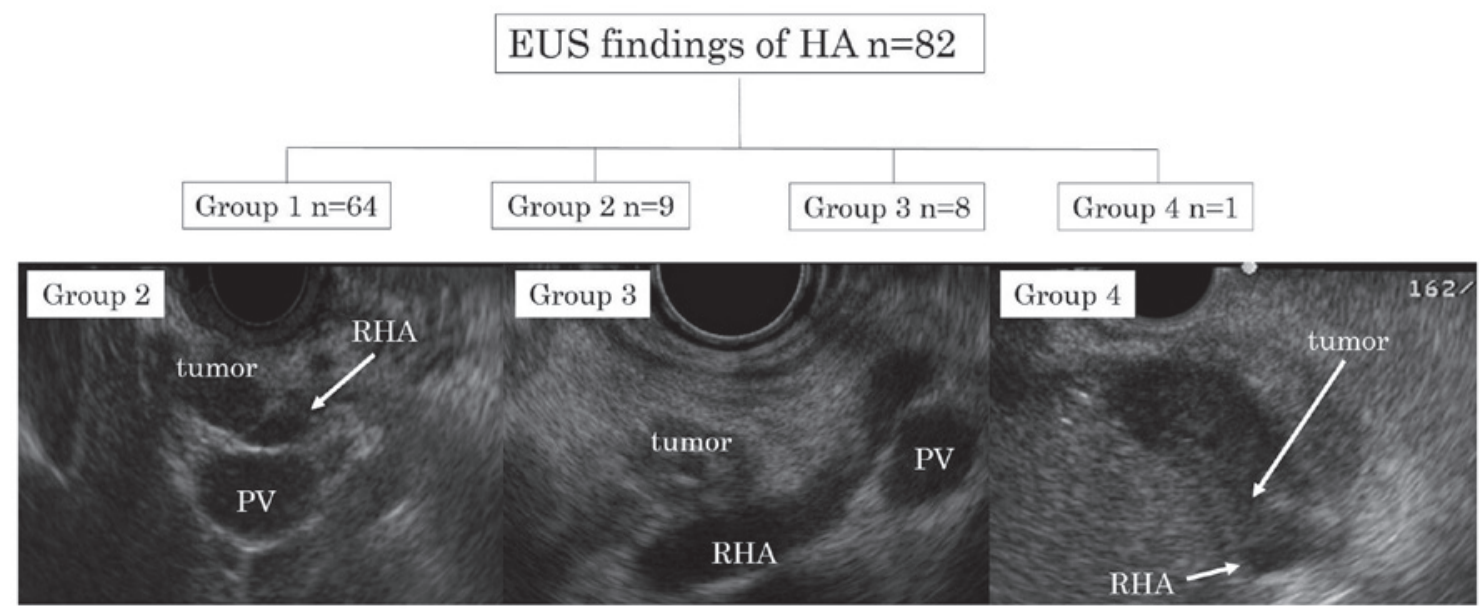

Figure 1. Flow chart of study patients ( $\mathrm{n}=$ number of patients). We divided patients into four groups according to EUS findings of the HA and PV.

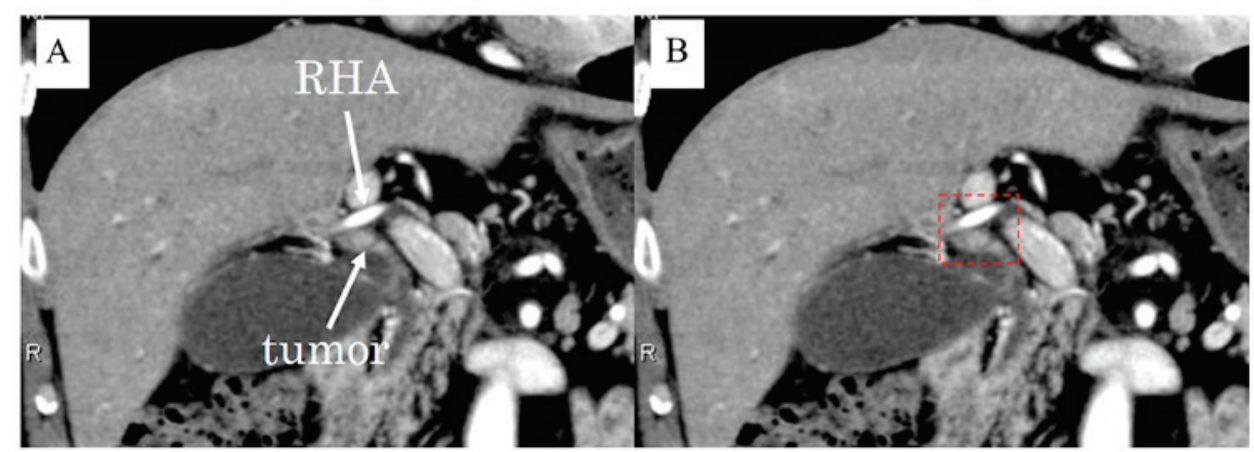

Figure 2. CT findings in Case 6. (A and B) cases as showing 'no invasion' when a boundary was confirmed between the vessel (HA or PV) and tumor on CT.

(GF-UGT240 or GF-UCT260; Olympus Medical Systems, Tokyo, Japan) connected to an ultrasound device (Prosound a10; Aloka, Tokyo, Japan or EU-ME2 Premier Plus; Olympus Medical Systems). EUS was performed under conscious sedation using intravenous midazolam and pethidine hydrochloride. We visualized and evaluated the HA and PV using a careful technique as we have reported previously (4). We evaluated entire HA From the proper HA to the left and right HA. We evaluated EUS findings of the HA and PV were evaluated and cases were divided into four groups by two experienced endosonographers, as follows: Group 1, obvious hyperechoic tissue between tumor and vessel; Group 2, close proximity between tumor and vessel without loss of hyperechoic tissue; Group 3, tumor and vessel contiguity with loss of hyperechoic tissue; and Group 4, encasement $>180^{\circ}$ (Fig. 1).

CT findings for the HA and PV were evaluated by two radiologists. On CT, we defined cases as showing 'invasion' when no boundary was evident between the tumor and vessel (Figs. 2 and 3).

Histological evaluation. After fixation in $10 \%$ formalin, the surgical specimen was cut transversely into 5-mm slices and slices of serial sections were added as needed. Each slice was sectioned and stained with hematoxylin and eosin (H\&E). Two pathologists performed examinations for resected vessels and diagnosed histological invasion when tumor was found to have infiltrated to the vascular adventitia (Fig. 4). If no vascular invasion was present, the distance between the tumor and vascular adventitia was measured pathologically using a microscope in cases whose the HA and PV had been resected (Figs. 5 and 6). In cases whose the HA was able to be separated from the tumor intraoperatively despite being close on EUS, we analyzed the clinical course and local recurrence rate. Pathological findings were described using the TNM Classification of Malignant Tumors by the International Union Against Cancer (7).

\section{Results}

Patients included 58 men and 23 women, with a median age of 70 years (range, 44-86 years). Patients underwent surgery for intrahepatic/extrahepatic cholangiocarcinoma $(n=2 / 54)$, gallbladder carcinoma $(n=21)$, cystic duct carcinoma $(n=4)$, or lymph node recurrence of cholangiocarcinoma $(n=1)$. One case involved extrahepatic cholangiocarcinoma concomitant with gallbladder carcinoma. Histological type included 79 adenocarcinomas and 3 adenosquamous carcinomas (Table I). Operative procedures for these patients are shown in Table II. Twenty-seven patients underwent pancreatoduodenectomy, while 16 patients underwent right hepatectomy, caudal lobectomy, and bile duct resection. Patient groupings according to EUS findings for the HA were: Group 1, 64 patients; Group 2, 9 patients; Group 3,8 patients; and Group 4, 1 patient. 


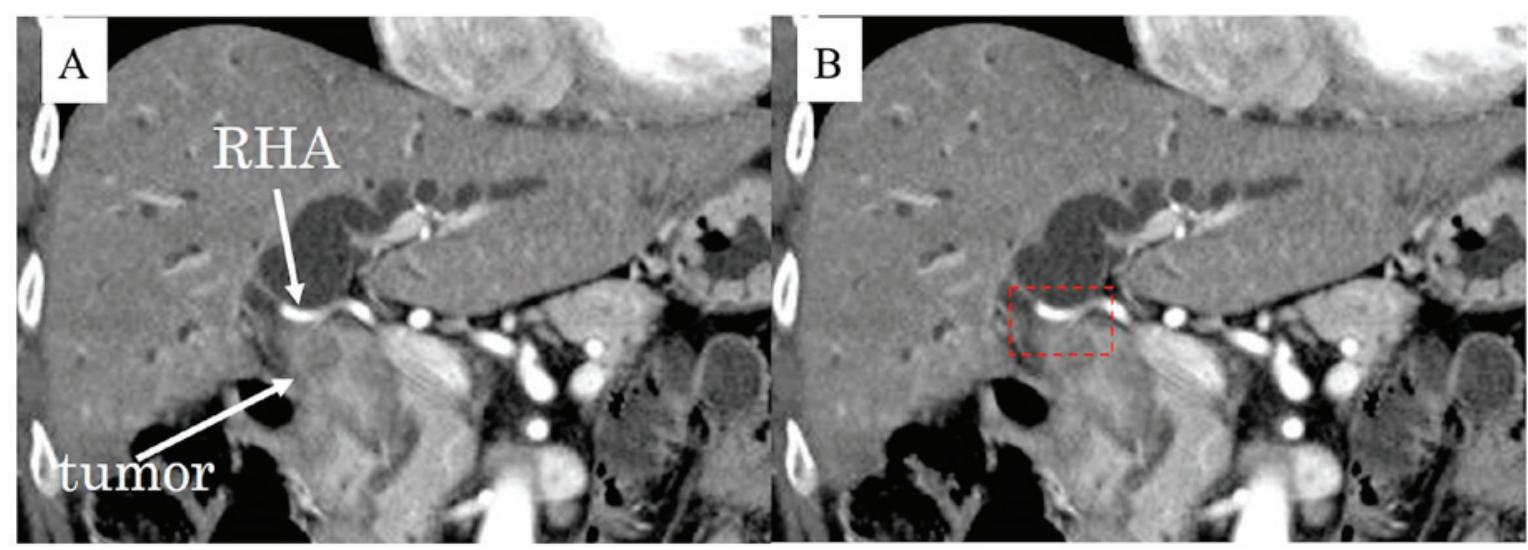

Figure 3. CT findings in Case 9. (A and B) We defined cases as showing 'invasion' when no boundary was evident between the tumor and vessel (HA or PV) on CT.

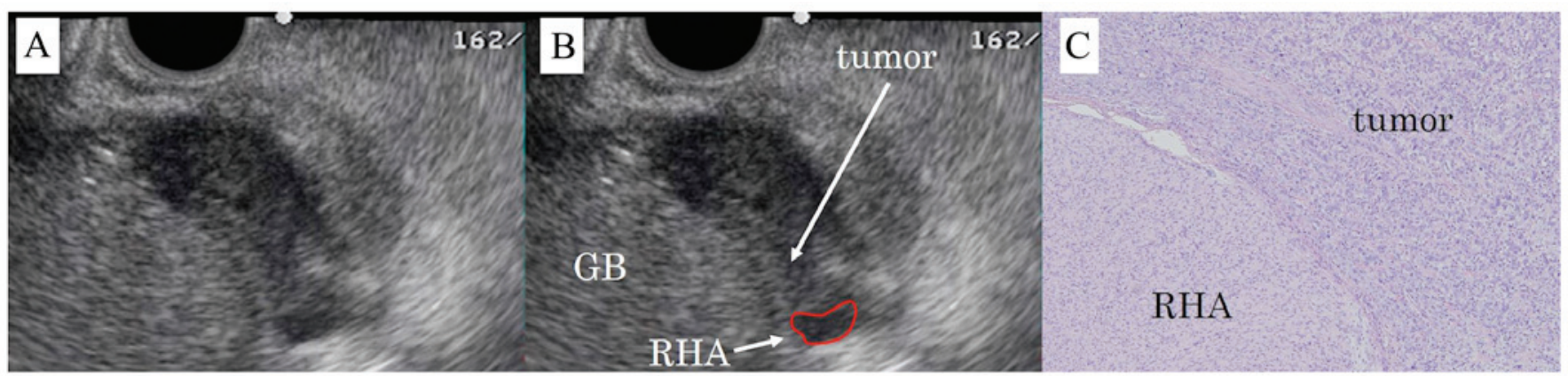

Figure 4. EUS and pathological findings of Group 4. (A and B) A Group 4 case showing encasement $>180^{\circ}$ on EUS. The area surrounded by the red curve is the RHA. GB, gallbladder. (C) Histological findings of resected specimen show tumor infiltrating into RHA adventitia. H\&E staining, x100.

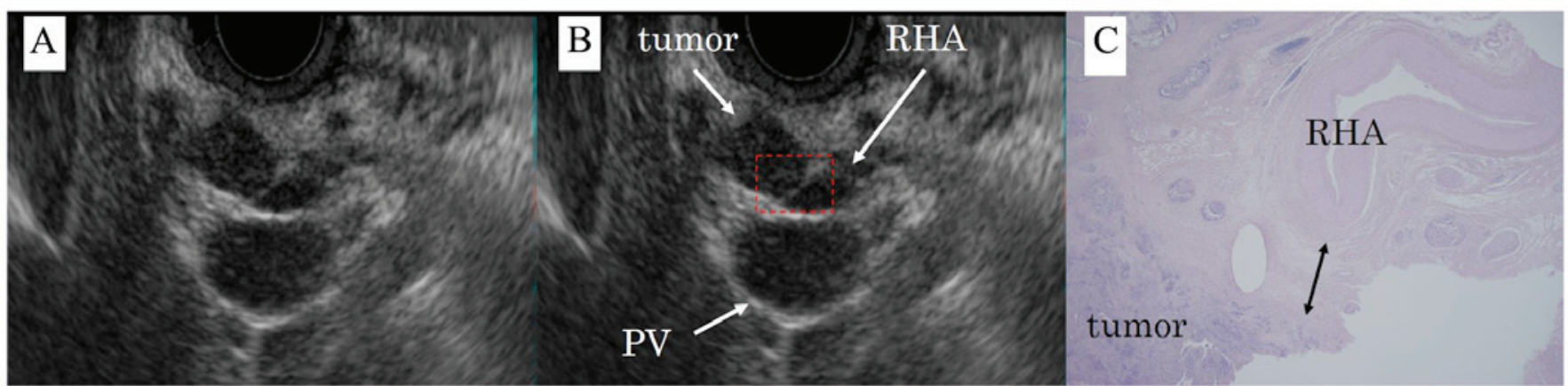

Figure 5. EUS and pathological findings of Group 2 (Case 4). (A and B) Group 2 cases show close proximity between the tumor and vessel without loss of hyperechoic tissue. (C) The distance between the RHA and the bile duct of tumor site on the pathological specimen is 1,300 $\mu \mathrm{m}$. H\&E staining, x20.

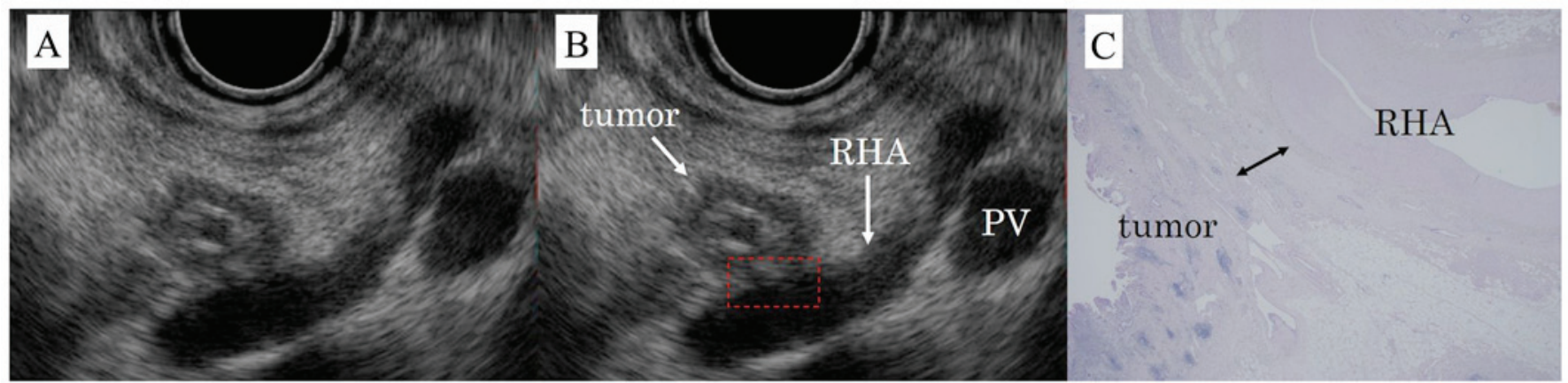

Figure 6. EUS and pathological findings of Group 3 (Case 14). (A and B) Group 3 cases show tumor and vessel contiguity with loss of hyperechoic tissue. (C) The distance between the RHA and the bile duct of the tumor site on the pathological specimen is $474 \mu \mathrm{m}$. H\&E staining, x20. 
We then compared EUS results with findings from resected specimens. No cases in Group 1 showed invasion from intraoperative macroscopic findings or histological findings of resected specimens. Naturally, the single case in Group 4 showed histological invasion (Fig. 4). These results were not inconsistent with preoperative EUS findings.

We thus performed detailed examinations of Groups 2 and 3 , in which the tumor was close to the HA but no obvious encasement was evident (Tables III, IV). In preoperative evaluation by CT, 2 of 9 cases in Group 2 (22.2\%) and 7 of 8 cases in Group $3(87.5 \%)$ were predicted positive for HA invasion. As shown in Tables III and IV, the HA was more difficult to evaluate on CT in cases from Group 3 than in cases from Group 2, naturally. In Group 2, the HA could be separated from the tumor during surgery in 5 cases, whereas 4 cases underwent combined HA resection. Local recurrence was seen in 1 of the 5 cases in which the HA was separable from the tumor (20\%). Distances between the HA and the bile duct of the tumor site in the pathological specimens of the 4 cases that underwent combined HA resection were 710, 1,200, 1,300 and 2,300 $\mu \mathrm{m}$. Among these, local recurrence was observed in 1 case. Group 3 included 5 cases in which the HA could be separated from the tumor during surgery, and 3 cases that underwent combined HA resection. Distances between the HA and the bile duct of the tumor site on the pathological specimens of the 3 cases with combined HA resection were 0 , 200 and $474 \mu \mathrm{m}$. Of these, local recurrence was seen in the case with a distance of $474 \mu \mathrm{m}$. In Group 3 cases, it was confirmed that the distance between the tumor and the HA was close compared to Group 2 on the pathological specimen. Normal hyperechoic tissue between the tumor and vessel disappeared at distances of $474-710 \mu \mathrm{m}$ according to the results. We could not visualized the boundary between the tumor and the HA in group 3 cases by convex EUS. No clinical differences in separation rates were evident between cases in Groups 2 and 3 . Among the 10 cases from Groups 2 and 3 in which the HA and tumor were able to be separated during surgery, only 1 case showed local recurrence, and no significant difference in local recurrence rate was evident between Groups 2 and 3. All cases from Groups 2 and 3 either showed no histological invasion or could be separated from the tumor intraoperatively. When the tumor could be separated from the HA, circumferential resection margins were also negative for cancer cells on histological examination.

We also investigated PV invasion (Table V). One case in Group 2 underwent combined PV resection. The distance between the PV and the bile duct of the tumor site on pathological specimens was $2,000 \mu \mathrm{m}$. In Group $3(n=6)$, the PV could be separated from the tumor during surgery in 1 case, and 1 case underwent combined PV resection without histological infiltration; all the remaining cases showed histological invasion. Among the 6 cases in which the tumor and PV appeared in contact with each other on EUS (Group 3), 4 cases $(66.7 \%$ ) showed PV invasion. This result differed from the examination of the HA.

\section{Discussion}

For patients with malignant biliary tract neoplasm, surgical resection is the only chance for cure (3). Accurate
Table I. Clinicopathological features of patients in this study.

\begin{tabular}{lc}
\hline Characteristics & $\mathrm{n}$ \\
\hline Males/females & $58 / 23$ \\
Age, years, median (range) & $70(44-86)$ \\
Location & \\
Extrahepatic bile duct (Bp/Bd) & $21 / 33$ \\
Gallbladder (Gn/Gb/Gf/C) & $5 / 4 / 12 / 4$ \\
Intrahepatic bile duct & 2 \\
Recurrence of cholangiocarcinoma & 1 \\
(lymph node) & \\
Histological type & $79 / 3$ \\
Adenocarcinoma/adenosquamous & \\
carcinoma & \\
Stage (UICC 7th) & \\
0/I/IA/IB/II/IIA/IIB/III/IIIA/IIIB/ & $1 / 3 / 6 / 7 / 12 / 9 / 16 / 18 / 2 / 2 / 4$ \\
IV/IVA/IVB &
\end{tabular}

$\mathrm{Bp}$, extrahepatic bile ducts, perihilar; Bd, extrahepatic bile ducts, distal; Gn, neck of the gallbladder; Gb, body of the gallbladder; Gf, fundus of the gallbladder; $\mathrm{C}$, cystic duct.

Table II. Operative procedures in this study.

\begin{tabular}{lr} 
Operative procedure & $\mathrm{n}$ \\
\hline PD & 27 \\
BDR & 3 \\
Cholecystectomy & 3 \\
Cholecystectomy+gallbladder bed resection & 6 \\
Cholecystectomy+gallbladder bed resection+BDR & 3 \\
Right hepatectomy+CHx+BDR & 16 \\
Right hepatectomy+CHx+BDR+PD & 3 \\
Left hepatectomy+CHx+BDR & 10 \\
Left hepatectomy+CHx+BDR+PD & 3 \\
Right trisectionectomy+PD & 1 \\
Left trisectionectomy & 3 \\
Central bisectomy+PD & 1 \\
CHx+PD & 1 \\
Lymphadenectomy & 1
\end{tabular}

PD, pancreatoduodenectomy; BDR, Bile duct resection; $\mathrm{CHx}$, caudal lobectomy.

evaluation of vascular invasion is thus critical for choosing the most appropriate surgical procedure. The evaluation for resectability requires careful patient selection and meticulous interpretation of imaging studies (8). EUS offers marked advantages over CT and other imaging modalities in allowing assessment of echo structures in lesions $<1 \mathrm{~cm}$ in diameter (9). We have reported convex EUS as useful for the assessment of vascular invasion in cancers including the hepatic hilum (4). EUS provides high-resolution power without echo attenuation 
Table III. Characteristics of clinical findings and postoperative course in Group 2.

\begin{tabular}{|c|c|c|c|c|c|c|}
\hline Case & Location & Vessel & $\begin{array}{c}\text { CT } \\
\text { diagnosis }\end{array}$ & $\begin{array}{l}\text { Histological } \\
\text { diagnosis }\end{array}$ & $\begin{array}{l}\text { Distance between } \\
\text { tumor and HA }\end{array}$ & $\begin{array}{c}\text { Postoperative } \\
\text { follow-up (months) }\end{array}$ \\
\hline 1 & $\mathrm{Bd}$ & RHA & - & - & $710 \mu \mathrm{m}$ & 85 \\
\hline 2 & $\mathrm{Bp}$ & RHA & - & & N/A & 4 (local recurrence) \\
\hline 3 & $\mathrm{Bd}$ & RHA & - & - & $1,200 \mu \mathrm{m}$ & 31 (peritoneal recurrence) \\
\hline 4 & Gn & RHA & - & - & $1,300 \mu \mathrm{m}$ & 2 (local recurrence) \\
\hline 5 & $\mathrm{Bp}$ & RHA & + & & N/A & 68 \\
\hline 6 & $\mathrm{Bp}$ & RHA & - & - & $2,300 \mu \mathrm{m}$ & $11^{\mathrm{a}}$ \\
\hline 7 & $\mathrm{Bp}$ & RHA & - & & N/A & 11 (peritoneal recurrence) \\
\hline 8 & $\mathrm{Bd}$ & RHA & - & & $\mathrm{N} / \mathrm{A}$ & 13 \\
\hline 9 & $\mathrm{C}$ & RHA & + & & $\mathrm{N} / \mathrm{A}$ & 12 \\
\hline
\end{tabular}

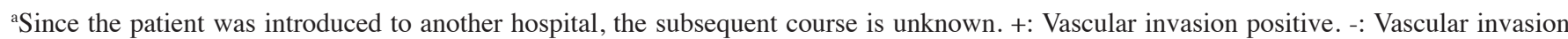
negative. N/A: We could not evaluate the distance between the RHA and the bile duct of the tumor site on the pathological specimen because the HA could be separated from the tumor during surgery.

Table IV. Characteristics of clinical findings and postoperative course in Group 3.

\begin{tabular}{|c|c|c|c|c|c|c|}
\hline Case & Location & Vessel & $\begin{array}{c}\text { CT } \\
\text { diagnosis }\end{array}$ & $\begin{array}{c}\text { Histological } \\
\text { diagnosis }\end{array}$ & $\begin{array}{c}\text { Distance between } \\
\text { tumor and HA }\end{array}$ & $\begin{array}{c}\text { Postoperative } \\
\text { follow-up (months) }\end{array}$ \\
\hline 10 & $\mathrm{Bp}$ & RHA & + & & N/A & $3^{\mathrm{a}}$ \\
\hline 11 & $\mathrm{Bp}$ & RHA & + & & N/A & 25 (LN recurrence) \\
\hline 12 & $\mathrm{Bd}$ & MHA & + & & N/A & 9 (liver recurrence) \\
\hline 13 & $\mathrm{Bp}$ & RHA & + & - & 0 & $39^{\mathrm{a}}$ \\
\hline 14 & $\mathrm{Bp}$ & RHA & + & - & $474 \mu \mathrm{m}$ & 7 (local recurrence) \\
\hline 15 & $\mathrm{Bp}$ & RHA & + & & N/A & 22 \\
\hline 16 & $\mathrm{Bd}$ & RHA & + & - & $200 \mu \mathrm{m}$ & 24 ( $\mathrm{LN}$ recurrence) \\
\hline 17 & $\mathrm{Bd}$ & RHA & - & & N/A & 37 \\
\hline
\end{tabular}

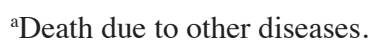

Table V. Clinical features of cases with suspected PV invasion.

\begin{tabular}{|c|c|c|c|c|c|}
\hline Case & Location & Vessel & EUS classification & CT diagnosis & $\begin{array}{c}\text { Distance between } \\
\text { tumor and PV }\end{array}$ \\
\hline 4 & Gf & PV & Group 2 & + & $2,000 \mu \mathrm{m}$ \\
\hline 5 & $\mathrm{Bp}$ & LPV & Group 3 & + & Invasion \\
\hline 11 & $\mathrm{Bp}$ & LPV & Group 3 & + & $385 \mu \mathrm{m}$ \\
\hline 12 & $\mathrm{Bd}$ & PV & Group 3 & - & Invasion \\
\hline 15 & $\mathrm{Bp}$ & RPV & Group 3 & - & N/A \\
\hline 18 & Gn & PV & Group 3 & + & Invasion \\
\hline 19 & $\mathrm{Bp}$ & LPV & Group 3 & + & Invasion \\
\hline 20 & $\mathrm{Bp}$ & LPV & Group 4 & + & Invasion \\
\hline 21 & $\mathrm{Bd}$ & RPV & Group 4 & - & Invasion \\
\hline 22 & $\mathrm{Bp}$ & RPV & Group 4 & + & Invasion \\
\hline
\end{tabular}

LPV, left portal vein; RPV, right portal vein.

and without the influence of gastrointestinal gas, thanks to the close apposition of the echoendoscope to abdominal vessels (10). As a result, EUS is suited to the evaluation of vessel invasion. The accuracy of identifying vascular invasion 
by cholangiocarcinoma has been reported as $87-100 \%$ (11-14) for CT, whereas EUS offers $88-100 \%$ accuracy for predicting PV invasion and performs better than transabdominal US and angiography in this regard (15-17). However, those reports did not compare other imaging modalities and clinical courses in detail and we do not have clear criteria for vascular findings obtained by EUS. To the best of our knowledge, the present study represents the first report to compare EUS findings with histological findings from resected specimens and to analyze histological invasion, clinical course, and local recurrence rates in detail. Normal hyperechoic tissue between the tumor and vessel disappeared at distances of 474-710 $\mu \mathrm{m}$ according to the results of this study. When tumor was close to the HA on CT but no obvious encasement was visualized on convex EUS, all cases either showed no histological invasion or the HA was able to be separated from the tumor during the operation. However, the same could not be said for the PV, although the cause was unknown. When the tumor and PV appeared in contact on EUS (Group 3), 4 of the 6 cases (66.7\%) showed PV invasion. Miyazaki et al (18) reported on combined vascular resection for hilar cholangiocarcinoma. They found that cancer invasion into the adventitia was present in $80 \%$ of the 44 resected portal veins and $40 \%$ of the 9 resected hepatic arteries, and concluded that caution should be exercised when planning combined hepatic artery resection, because cancer invasion into the adventitia of the HA occurs in only about half of the patients despite clinical findings of apparent invasion. In that series, combined vascular resection was performed when cancer invasion to the vessels was diagnosed on the basis of both preoperative imaging and intraoperative macroscopic findings (18). Ebata et al also reported performing combined PV resection in 52 cases, 16 of which patients did not show PV invasion, despite the fact that all PV resections were carried out only after the PV adhered to and could not be freed from the tumor during surgery. In that report, the distance between the leading edge of the cancer and the outer layer of the adventitia ranged from 50 to $1,375 \mu \mathrm{m}$ (19). Assessing vascular invasion before surgery has thus been difficult. Compared with the HA, the PV is relatively easy to include in combined resection and reconstruction such as wedge resection is also simpler (19), so invasion to the $\mathrm{PV}$ is no longer considered a contraindication for surgery and is less important than the evaluation of arterial invasion. Vascular invasion of the HA is still a contraindication and combined resection and reconstruction of the HA is technically challenging (20). From the results of our study, we consider surgery when the tumor is close to the HA on CT but no obvious encasement is visualized on convex EUS. This study may offer a new indication in the preoperative evaluation of malignant biliary tract neoplasm. However, some limitations must be considered when interpreting the results of this retrospective study. Selection bias may have been present, because all patients underwent surgery. In addition, all data were retrospectively collected from a single center. Further studies are necessary to clarify the utility of our findings.

In conclusion, convex EUS appears useful for preoperative evaluation of malignant biliary tract neoplasm. We can consider surgery when the tumor is close to the HA on CT but there is no obvious encasement visualized by convex EUS.

\section{References}

1. Valle JW: Advances in the treatment of metastatic or unresectable biliary tract cancer. Ann Oncol 21 (Suppl 7): vii345-vii348, 2010.

2. Valle J, Wasan H, Palmer DH, Cunningham D, Anthoney A, Maraveyas A, Madhusudan S, Iveson T, Hughes S, Pereira SP, et al: Cisplatin plus gemcitabine versus gemcitabine for biliary tract cancer. N Engl J Med 362: 1273-12781, 2010.

3. Khan SA, Thomas HC, Davidson BR and Taylor-Robinson SD: Cholangiocarcinoma. Lancet 366: 1303-1314, 2005.

4. Hara K, Bhatia V, Hijioka S, Mizuno N and Yamao K: A convex EUS is useful to diagnose vascular invasion of cancer, especially hepatic hilus cancer. Dig Endosc 23 (Suppl 1): 26-28, 2011.

5. Yang R, Lu M, Qian X, Chen J, Li L, Wang J and Zhang Y: Diagnostic accuracy of EUS and CT of vascular invasion in pancreatic cancer: A systematic review. J Cancer Res Clin Oncol 140: 2077-2086, 2014.

6. Tellez-Avila FI, Chavez-Tapia NC, López-Arce G, Franco-Guzmán AM, Sosa-Lozano LA, Alfaro-Lara R, Chan-Nuñez C, Giovannini M, Elizondo-Rivera $J$ and Ramírez-Luna MA: Vascular invasion in pancreatic cancer: Predictive values for endoscopic ultrasound and computed tomography imaging. Pancreas 41: 636-638, 2012.

7. Sobin L, Gospodarowicz M and Wittekind C: UICC international union against cancer. In: TNM Classification of Malignant Tumours. Wiley-Blackwell, New York, pp118-126, 2009.

8. Lazaridis $\mathrm{KN}$ and Gores GJ: Cholangiocarcinoma. Gastroenterology 128: 1655-1667, 2005.

9. Irisawa A and Yamao K: Curved linear array EUS technique in the pancreas and biliary tree: Focusing on the stations. Gastrointest Endosc 69 (2 Suppl): S84-S89, 2009.

10. Mohamadnejad M, DeWitt JM, Sherman S, LeBlanc JK, Pitt HA, House MG, Jones KJ, Fogel EL, McHenry L, Watkins JL, et al: Role of EUS for preoperative evaluation of cholangiocarcinoma: A large single-center experience. Gastrointest Endosc 73: 71-78, 2011.

11. Unno M, Okumoto T, Katayose Y, Rikiyama T, Sato A, Motoi F, Oikawa M, Egawa S and Ishibashi T: Preoperative assessment of hilar cholangiocarcinoma by multidetector row computed tomography. J Hepatobiliary Pancreat Surg 14: 434-440, 2007.

12. Watadani T, Akahane M, Yoshikawa $\mathrm{T}$ and Ohtomo K: Preoperative assessment of hilar cholangiocarcinoma using multidetector-row CT: Correlation with histopathological findings. Radiat Med 26: 402-407, 2008.

13. Lee HY, Kim SH, Lee JM, Kim SW, Jang JY, Han JK and Choi BI: Preoperative assessment of resectability of hepatic hilar cholangiocarcinoma: Combined CT and cholangiography with revised criteria. Radiology 239: 113-121, 2006.

14. Endo I, Shimada H, Sugita M, Fujii Y, Morioka D, Takeda K, Sugae S, Tanaka K, Togo S, Bourquain H and Peitgen HO: Role of three-dimensional imaging in operative planning for hilar cholangiocarcinoma. Surgery 142: 666-675, 2007.

15. Sugiyama M, Hagi H, Atomi Y and Saito M: Diagnosis of portal venous invasion by pancreatobiliary carcinoma: Value of endoscopic ultrasonography. Abdom Imaging 22: 434-438, 1997.

16. Tio TL, Reeders JW, Sie LH, Wijers OB, Maas JJ, Colin EM and Tytgat GN: Endosonography in the clinical staging of Klatskin tumor. Endoscopy 25: 81-85, 1993.

17. Mukai H, Nakajima M, Yasuda K, Mizuno S and Kawai K: Evaluation of endoscopic ultrasonography in the pre-operative staging of carcinoma of the ampulla of Vater and common bile duct. Gastrointest Endosc 38: 676-683, 1992.

18. Miyazaki M, Kato A, Ito H, Kimura F, Shimizu H, Ohtsuka M, Yoshidome H, Yoshitomi H, Furukawa K and Nozawa S: Combined vascular resection in operative resection for hilar cholangiocarcinoma: Does it work or not? Surgery 141: 581-588, 2007.

19. Ebata T, Nagino M, Kamiya J, Uesaka K, Nagasaka T and Nimura Y: Hepatectomy with portal vein resection for hilar cholangiocarcinoma: Audit of 52 consecutive cases. Ann Surg 238: 720-727, 2003.

20. Matsuyama R, Mori R, Ota Y,Homma Y, Kumamoto T, Takeda K, Morioka D, Maegawa J and Endo I: Significance of vascular resection and reconstruction in surgery for hilar cholangiocarcinoma: With special reference to hepatic arterial resection and reconstruction. Ann Surg Oncol 23 (Suppl 4): S475-S484, 2016. 